OPEN ACCESS

Edited by:

Sveva Bollini,

University of Genoa, Italy

Reviewed by:

Lucio Barile,

University of Zurich, Switzerland

Marta Tapparo,

University of Turin, Italy

${ }^{*}$ Correspondence:

Mahmood Khan

mahmood.khan@osumc.edu

${ }^{\dagger}$ These authors have contributed equally to this work

Specialty section:

This article was submitted to

Stem Cell Research,

a section of the journal

Frontiers in Cell and Developmental

Biology

Received: 04 November 2019

Accepted: 14 February 2020

Published: 06 March 2020

Citation:

Dougherty JA, Patel N, Kumar N, Rao SG, Angelos MG, Singh H, Cai C and Khan M (2020) Human Cardiac Progenitor Cells Enhance Exosome Release and Promote Angiogenesis

Under Physoxia.

Front. Cell Dev. Biol. 8:130.

doi: 10.3389/fcell.2020.00130

\section{Human Cardiac Progenitor Cells Enhance Exosome Release and Promote Angiogenesis Under Physoxia}

\begin{abstract}
Julie A. Dougherty ${ }^{1,2 t}$, Nil Patel ${ }^{1+}$, Naresh Kumar ${ }^{1}$, Shubha Gururaja Rao ${ }^{3}$, Mark G. Angelos ${ }^{1}$, Harpreet Singh ${ }^{2,3}$, Chuanxi Cai ${ }^{4}$ and Mahmood Khan 1,2,3*

${ }^{1}$ Department of Emergency Medicine, The Ohio State University Wexner Medical Center, Columbus, OH, United States, ${ }^{2}$ Dorothy M. Davis Heart Lung and Research Institute, The Ohio State University Wexner Medical Center, Columbus, OH, United States, ${ }^{3}$ Department of Physiology and Cell Biology, The Ohio State University Wexner Medical Center, Columbus, $\mathrm{OH}$, United States, ${ }^{4}$ Division of Cardiac Surgery, Department of Surgery, The Ohio State University Wexner Medical Center, Columbus, $\mathrm{OH}$, United States
\end{abstract}

Studies on cardiac progenitor cells (CPCs) and their derived exosomes therapeutic potential have demonstrated only modest improvements in cardiac function. Therefore, there is an unmet need to improve the therapeutic efficacy of CPCs and their exosomes to attain clinically relevant improvement in cardiac function. The hypothesis of this project is to assess the therapeutic potential of exosomes derived from human CPCs (hCPCs) cultured under normoxia $\left(21 \% \mathrm{O}_{2}\right)$, physoxia $\left(5 \% \mathrm{O}_{2}\right)$ and hypoxia $\left(1 \% \mathrm{O}_{2}\right)$ conditions. hCPCs were characterized by immunostaining of CPC-specific markers (NKX-2.5, GATA-4, and c-kit). Cell proliferation and cell death assay was not altered under physoxia. A gene expression qPCR array (84 genes) was performed to assess the modulation of hypoxic genes under three different oxygen conditions as mentioned above. Our results demonstrated that very few hypoxia-related genes were modulated under physoxia (5 genes upregulated, 4 genes down regulated). However, several genes were modulated under hypoxia (23 genes upregulated, 9 genes downregulated). Furthermore, nanoparticle tracking analysis of the exosomes isolated from hCPCs under physoxia had a 1.6-fold increase in exosome yield when compared to normoxia and hypoxia conditions. Furthermore, tube formation assay for angiogenesis indicated that exosomes derived from hCPCs cultured under physoxia significantly increased tube formation as compared to no-exosome control, $21 \% \mathrm{O}_{2}$, and $1 \% \mathrm{O}_{2}$ groups. Overall, our study demonstrated the therapeutic potential of physoxic oxygen microenvironment cultured hCPCs and their derived exosomes for myocardial repair.

Keywords: cardiac progenitor cells, stem cells, hypoxia, extracellular vesicles, angiogenesis, cardiac repair

\section{INTRODUCTION}

Myocardial infarction (MI) is responsible for the death of one American every $40 \mathrm{~s}$ (Benjamin et al., 2017). MI is caused by a limited supply of blood and oxygen to the heart, which leads to cardiac dysfunction, fibrosis, and, ultimately, heart failure. Post-MI, there is a permanent loss of cardiomyocytes and scar tissue formation that results in irreversible damage and maladaptation, 
which affects cardiac function (Prabhu and Frangogiannis, 2016). Existing therapies have been used to prevent additional damage to the heart muscle and reduce the risk of future MI, however, they only slow the progression to heart failure. Therefore, effective cardiac repair is essential to restore function of the heart following MI. Currently, cell-based therapies to aid in cardiac tissue regeneration, such as the application of stem cells, serve to be the most promising therapeutic option today (Krishna et al., 2011; Choi et al., 2015). Nevertheless, optimal cell type and conditions have not yet been identified for clinically relevant repair.

Stem cells have been previously used as a cell-based therapy to restore cardiac function. Embryonic stem cells (ESCs) hold promise as a cellular therapy because they are pluripotent; however, the clinical use of this cell line raises several ethical issues and political controversies. Today, adult stem cells are the only cells utilized as a cell-based therapy to treat MI in the United States (Le and Chong, 2016). Cardiac progenitor cells (CPCs) have been of particular interest for stem cell therapy in the treatment of MI since they have the ability to differentiate into three cardiac lineages: cardiomyocytes, smooth muscle cells, and endothelial cells. However, cell survival post-transplantation is very poor. Interestingly, despite this, moderate improvements in cardiac function are observed (den Haan et al., 2012; Noort et al., 2012; van der Spoel et al., 2012; Zuo et al., 2012; Bao et al., 2017; Wu et al., 2017), which points toward a paracrine mechanism of repair.

Extracellular vesicles, including exosomes and microparticles, have recently become of particular interest as they have been identified to be key players in paracrine signaling (Hergenreider et al., 2012; Raposo and Stoorvogel, 2013; Maas et al., 2017; Sullivan et al., 2017) and have become a major focus of research in this area. Exosomes are 50-150 nm (YanezMo et al., 2015) vesicles formed by inward budding of endosomal membranes (Thery, 2011). Microvesicles are larger, 100-1000 nm (Cocucci and Meldolesi, 2015), and directly bud from the cell membrane (Colombo et al., 2014). Despite their differences, practical isolation of the two types of particles is difficult and we will refer to exosomes and microvesicles collectively as EVs. These EVs are nanoparticles that contain lipids (Record et al., 2014), proteins (Choi et al., 2015), and nucleic acids (Gezer et al., 2014; Ahadi et al., 2016; Ohno and Kuroda, 2016), which are specifically packaged depending on their source cell type and microenvironment (Xiao et al., 2016; Dougherty et al., 2017). EVs have already demonstrated therapeutic potential in treating the heart postMI. In 2010, a study demonstrated that exosomes secreted by MSCs reduce myocardial ischemia/reperfusion injury via a mouse Langendorff heart model. In this study, exosomes were administered prior to reperfusion and results showed decreased infarct size (Lai et al., 2010). Another study demonstrated proangiogenic activities of atrial appendage CPC-derived EVs both in vitro and in vivo (Barile et al., 2014). Specifically, this study showed that these EVs inhibited cardiomyocyte apoptosis and enhanced angiogenesis, as they were enriched in miRNAs with anti-apoptotic and proangiogenic activities
(Barile et al., 2014). Oxygen concentration used for culture were not reported for either study, thus, one then assumes cells were cultured at standard laboratory cell culture conditions of $21 \% \mathrm{O}_{2}$.

The role of oxygen is severely critical in the survival of any type of cell line including stem cells. Oxygen controls the cellular microenvironment, serving as both a metabolic substrate and a signaling molecule (Abdollahi et al., 2011). Standard cell culturing protocols utilize $21 \% \mathrm{O}_{2}$ for culturing and maintaining the cells. These conditions are considered normoxia, as it is the atmospheric level of oxygen. On the contrary, in an in vivo scenario, the oxygen microenvironments for cells are much lower than $21 \% \mathrm{O}_{2}$. The relative oxygen concentration of arterial blood is approximately $12 \%$ and most tissue is around 3.4 to $6.8 \%$ with concentration varying based on location (reviewed in Abdollahi et al., 2011; McKeown, 2014). McKeown proposes that $5 \% \mathrm{O}_{2}$ be termed "physoxia" as it is a better estimate of tissue oxygenation (McKeown, 2014). Conversely, hypoxic culture of cells affects their functional behavior and can have therapeutic applications. In two different studies, hypoxic culture $\left(1 \% \mathrm{O}_{2}\right)$ of adipose stromal cells enhanced cytokine production and increased their angiogenic properties (Rehman et al., 2004; Thangarajah et al., 2009). Also, hypoxic culture $\left(2 \% \mathrm{O}_{2}\right)$ of stem cells has demonstrated various benefits including a 30fold increase in the expansion of cells compared to normoxic conditions in a study utilizing human bone marrow-derived mesenchymal stem cells (BM-MSCs) (Grayson et al., 2007). Another study demonstrated that hypoxic preconditioning (1\% $\mathrm{O}_{2}$ hypoxia for $6 \mathrm{~h}$ ) enhanced CPC function by demonstrating increased invasion ability and pro-survival pathway activation (Hernandez et al., 2018). Thus, culturing cells in vitro at physoxic and hypoxic conditions mimics the in vivo microenvironment and that of the ischemic heart post-MI. Additionally, previous studies have reported that short-term hypoxic culture resulted in enhanced exosome release from mouse CPCs and altered their molecular contents (Gray et al., 2015; Barile et al., 2017). Therefore, the focus of this paper was to investigate whether low-oxygen culturing ( 5 or $1 \% \mathrm{O}_{2}$ ) of hCPCs modulates hypoxia signaling genes and their derived exosomes for cardiac repair post-MI.

\section{MATERIALS AND METHODS}

\section{Culture of Cardiac Progenitor Cells}

Human cardiac progenitor cells (hCPCs) were isolated from the right atrial appendage and sorted for expression of c-kit cell surface marker, as described previously (Zhang et al., 2017). Cells were used at passage 7-10 for these studies. Cells were initially cultured for $48 \mathrm{~h}$ at normoxic conditions $\left(37^{\circ} \mathrm{C}, 21 \% \mathrm{O}_{2}\right)$ then placed in medium with exosome-depleted FBS (SBI, Palo Alto, CA, United States) and continuously cultured at normoxic condition of $21 \% \mathrm{O}_{2}$ physoxic condition of $5 \% \mathrm{O}_{2}$ or hypoxic condition of $1 \% \mathrm{O}_{2}$ using a controlled C-chamber incubator (ProOx P110 $\mathrm{O}_{2}$ Controllers, BioSperix, Parish, NY, United States). Media was refreshed every other day, retaining $20 \%$ of conditioned media. Phase-contrast images 
were captured using a DM IL LED microscope and MC170 HD digital camera (Leica Microsystems, Inc., Buffalo Grove, IL, United States).

\section{Immunofluorescent Staining}

Cells were seeded on glass cover-slips coated with $0.5 \%$ gelatin and cultured at 21,5 , and $1 \% \mathrm{O}_{2}$ for $48 \mathrm{~h}$. Cells were fixed with $4 \%$ paraformaldehyde in PBS for $10 \mathrm{~min}$ at room temperature, permeabilized with $0.25 \%$ Triton-X-100 in PBS for $20 \mathrm{~min}$ at $4^{\circ} \mathrm{C}$, and incubated overnight at $4^{\circ} \mathrm{C}$ with antibodies in antibody dilution buffer $(1 \% \mathrm{w} / \mathrm{v}$ BSA, $0.3 \%$ Triton-X-100 in PBS): NKX-2.5 (1:25, PA5-49431, Invitrogen, Carlsbad, CA, United States), GATA-4 (1:300, PA1-102, Invitrogen, Carlsbad, CA, United States), and c-kit (1:25, MA5-12944, Invitrogen, Carlsbad, CA, United States). Cells were washed three times for $5 \mathrm{~min}$ with PBS, treated with secondary antibody (1:500 anti-rabbit IgG Alexa Fluor 488 ab150077 or anti-mouse IgG Alexa Fluor 488 ab 150113, Abcam, Cambridge, MA, United States), and incubated in the dark for $2 \mathrm{~h}$ at room temperature. Cover-slips were washed three times for $5 \mathrm{~min}$ with PBS. F-actin was stained using ActinRed $^{\mathrm{TM}} 555$ ReadyProbes $^{\mathrm{TM}}$ reagent (R37112, Invitrogen, Eugene, OR, United States) and nuclei were stained with NucBlue $^{\mathrm{TM}}$ Live Cell Stain ReadyProbes ${ }^{\mathrm{TM}}$ reagent (R37605, Invitrogen, Eugene, OR, United States) for $30 \mathrm{~min}$ at room temperature. Cover-slips were washed a final time, mounted with ProLong ${ }^{\mathrm{TM}}$ Glass Antifade Mountant (Invitrogen, Eugene, OR, United States) and allowed to cure for $24 \mathrm{~h}$. Imaged were acquired with a FluoView 1000 Filter Confocal Microscope (Olympus, Center Valley, PA, United States). Images were median-filtered (Singh et al., 2012, 2013) and analyzed by FIJI software.

\section{Cell Proliferation Assay}

The proliferation of hCPCs was performed using XTT reagent (Cayman Chemical, Ann Arbor, MI, United States) for cells cultured at 21,5 , and $1 \% \mathrm{O}_{2}$. Briefly, 6,000 cells were seeded in replicate wells of 96-well plates for analysis at time 0 and after $24 \mathrm{~h}$. XTT reagent was prepared per the manufacturer's instructions, mixed with cells and media blanks, and incubated at $37^{\circ} \mathrm{C}$ at their respective oxygen concentrations for $2 \mathrm{~h}$ then read with a spectrophotometer at $450 \mathrm{~nm}$ for $1 \mathrm{~s}$ (Victor300, Perkin Elmer, Waltham, MA, United States). Absorbance values were blank-corrected and proliferation was calculated relative to their time 0 value. Data are plotted as fold increase relative to time 0 , mean $\pm \mathrm{SD}, n=4$.

\section{Apoptosis Flow Cytometry}

Cells were cultured at 21,5 , and $1 \% \mathrm{O}_{2}$ for $48 \mathrm{~h}$ then harvested for staining with the ApoDETECT AnnexinV-FITC kit (Invitrogen, Thermo Scientific, Waltham, MA, United States) to assess apoptosis without any additional stress. Cells were trypsinized, collected, and spun down $10 \mathrm{~min}$ at $800 \mathrm{~g}$. The cell pellet was resuspended in $1 \mathrm{ml}$ ice-cold PBS and transferred to a $1.5 \mathrm{ml}$ microcentrifuge tube and spun down $1 \mathrm{~min}$ at $3000 \mathrm{rpm}$. The cell pellet was resuspended in 1X binding buffer and counted, volume was adjusted so cell density was $2-5 \times 10^{5}$ cells $/ \mathrm{ml}$. $190 \mu \mathrm{l}$ cell suspension was combined with $10 \mu \mathrm{l}$ of Annexin V-FITC, mixed gently, and incubated at room temperature for $10 \mathrm{~min}$. Cells were washed $1 \mathrm{X}$ with binding buffer, spun down $1 \mathrm{~min}$ at $3000 \mathrm{rpm}$, and resuspended in $190 \mu \mathrm{l}$ binding buffer. $10 \mu \mathrm{l}$ of $20 \mu \mathrm{g} / \mathrm{ml}$ propidium iodide stock solution was added to cells and incubated at room temperature for $10 \mathrm{~min}$. Cells were spun down $1 \mathrm{~min}$ at $3000 \mathrm{rpm}$ and resuspended in $200 \mu \mathrm{l}$ of PBS. Cells were analyzed by flow cytometry using a FACS Calibur flow cytometer (Becton Dickinson, Franklin Lakes, NJ, United States), with single dye controls determining gate parameters. Apoptotic cells are positive for Annexin V-FITC and negative for PI, dead cells are dual positive, and live cells show little to no fluorescence.

\section{Analysis of Gene Expression RNA Isolation}

Human CPCs were cultured at the three distinct oxygen concentrations for $48 \mathrm{~h}$. Cells were then lysed with TRIzol (Invitrogen, Carlsbad, CA, United States) for $3 \mathrm{~min}$ at room temp. Total RNA was then isolated using the Direct-zol RNA miniprep kit (Zymo Research, Irvine, CA, United States) per manufacturer's instructions with on-column DNA digestion and analyzed with a spectrophotometer (NanoDrop2000, Thermo Fisher, Pleasanton, CA, United States) for quantity and purity.

\section{cDNA Synthesis}

200 ng of total RNA was used to prepare cDNA using the RT $^{2}$ First Strand Kit (330404, Qiagen, Germantown, MD, United States) per manufacturer's protocol with synthesis performed for $1 \mathrm{~h}$ at $37^{\circ} \mathrm{C}$. Reactions were prepared from biological triplicates at the same time, with the same master mix.

\section{qPCR Analysis}

cDNA reactions were analyzed with $\mathrm{RT}^{2}$ SYBR Green ROX qPCR Mastermix (330523, Qiagen, Germantown, MD, United States) with the human hypoxia signaling pathway array (PAHS032Z, Qiagen, Germantown, MD, United States) according to manufacturer's instructions. Sample master mixes were thoroughly mixed and $25 \mu \mathrm{l}$ was added to each well of the array plate using an electronic pipette. The reaction was performed on a QuantStudio 3 thermocycler and Ct values were determined by the QuantStudio Design \& Analysis Software, version 1.4.1 (Thermo Fisher, Waltham, MA, United States). Relative quantification was performed using the $2^{-\Delta \Delta C t}$ method (Livak and Schmittgen, 2001) with normalization to five stably expressed housekeeping genes (ATR, CTSA, HIF1AN, LGALS3, RBPJ) and fold-change calculated relative to $21 \% \mathrm{O}_{2}$ cells. Data are shown mean $\pm \mathrm{SD}, n=3$.

\section{Isolation of EVs}

Human CPC-derived EVs were derived from the cell-conditioned medium collected at each oxygen concentration after culturing for $48 \mathrm{~h}$ in media supplemented with exosome-depleted FBS. Conditioned media was clarified with a $0.22 \mu \mathrm{m}$ syringe filter and concentrated with an Amicon-Ultra $100 \mathrm{kD}$ centricon. EVs were precipitated using ExoQuick-TC ${ }^{\circledast}$ (System Biosciences,PaloAlto, CA, United States) according to the manufacturer's protocol. EVs were then suspended in PBS and stored at $-80^{\circ} \mathrm{C}$. 


\section{Nanoparticle Tracking Analysis (NTA) of EVs}

An equal number of cells were seeded to $10 \mathrm{~cm}$ dishes and EVs were isolated from equal volumes of conditioned media from normoxic and low-oxygen hCPCs. Isolated EVs were suspended in equal volumes of PBS and analyzed for size, concentration, and distribution with a NanoSight NS300 (Malvern Panalytical, Malvern, United Kingdom). Camera setting and detection threshold were kept constant for all samples for direct comparison, samples were analyzed in triplicate, and a total of at least 1000 validated tracks per sample was measured (NTA v3.3, Malvern Panalytical, Malvern, United Kingdom). Curves represent mean of triplicate measurements.

\section{Cryo-TEM of Isolated EVs}

EVs isolated from 21,5 , and $1 \% \mathrm{O}_{2}$ culture were sent for Cryo-TEM processing and imaging, as described in Gao et al. (2014). Briefly, a FEI Vitrobot Mark IV plunge freezer (Thermo Scientific, Waltham, MA, United States), set at room temperature and $\sim 95 \%$ humidity, was used to prepare vitrified cryo-TEM specimens from the aqueous samples. About $2.5 \mu \mathrm{L}$ of the solution was applied to a TEM grid coated with lacey carbon film. After blotting using two filter papers, the grid was plunge-frozen in liquid ethane (Cavalier et al., 2009). The vitrified specimen was mounted onto a Gatan 626.DH cryo-TEM holder and transferred into a FEI Tecnai F20 TEM equipped with a Gatan twin blade retractable anti-contaminator. The cryo-TEM observation was carried out at $\sim-174^{\circ} \mathrm{C}$.

\section{Exosome Antibody Array of Isolated EVs}

Isolated EVs from 21,5 , and $1 \% \mathrm{O}_{2}$ cultured hCPCs were analyzed for expression of known exosome markers using the Exo-Check Exosome Antibody Array (System Biosciences, Palo Alto, CA, United States) per the manufacturer's instructions. Briefly, $50 \mu \mathrm{g}$ of EVs (by total EV protein) were added to 10X lysis buffer and vortexed. Labeling reagent was added, sample was vortexed, and incubated at room temperature with orbital shaking for $30 \mathrm{~min}$. Excess labeling reagent was removed with provided columns and lysate was added to Blocking Buffer and mixed by inversion. The array membrane was incubated in distilled water at room temperature for $2 \mathrm{~min}$, the water was then decanted, the lysate/blocking buffer mixture was added to the membrane, and it was incubated overnight at $4^{\circ} \mathrm{C}$ on a rocker. The lysate/blocking mixture was decanted, the membrane was washed at room temperature twice for $5 \mathrm{~min}$ with rocking. Detection Buffer was added to the membrane and incubated for $30 \mathrm{~min}$ at room temperature with rocking. Detection buffer was decanted and the membrane was washed three times for $5 \mathrm{~min}$ at room temperature. SuperSignal ${ }^{\mathrm{TM}}$ West Femto Maximum Sensitivity Substrate (Thermo Scientific, Waltham, MA, United States) was used to develop the membrane by mixing reagents $1: 1$ and incubating on the membrane for $5 \mathrm{~min}$. Imaging was performed with an Azure c600 Imaging System (Azure Biosystems, Dublin, CA, United States).

\section{Wound Healing (Scratch Assay) for Cell Migration}

Triplicate wells of a 24-well plate were seeded with bovine aortic endothelial cells (BAECs) cultured at $37^{\circ} \mathrm{C}, 5 \% \mathrm{CO}_{2}, 21 \% \mathrm{O}_{2}$, and grown to confluence. A scratch was made down the center of each well with a $200 \mu l$ standard pipet tip. Human CPC-derived EVs were added to cells at $100 \mu \mathrm{g} / \mathrm{mL}$ and imaged at 0 and $8 \mathrm{~h}$ time points. An EVOS FL Auto 2 (Thermo Scientific, Waltham, MA, United States) with a programmable stage was used to take images of the same fields over time. The wound area was analyzed for four fields per well with ImageJ by a blinded operator. The area of closure was calculated as $\mathrm{A}=(1-(n \mathrm{~h}$ area/ $0 \mathrm{~h}$ area $)) \mathrm{x}$ $100 \%$ per frame then averaged per well.

\section{Tube Formation Assay for Angiogenesis}

Bovine aortic endothelial cells cultured at $37^{\circ} \mathrm{C}, 21 \% \mathrm{O}_{2}$ were seeded in quadruplicate in Geltrex-coated wells on a 24well plate. Human CPC-derived EVs from normoxic $21 \% \mathrm{O}_{2}$, physoxic $\left(5 \% \mathrm{O}_{2}\right)$, hypoxic $\left(1 \% \mathrm{O}_{2}\right)$ conditions or an equal volume of PBS (No-EVs Control) were added to BAECs at $100 \mu \mathrm{g} / \mathrm{mL}$. Plates were incubated at normoxic conditions $\left(37^{\circ} \mathrm{C}, 5 \% \mathrm{CO}_{2}, 21 \% \mathrm{O}_{2}\right)$ for $16 \mathrm{~h}$. Wells were gently washed with PBS and fixed with $4 \%$ paraformaldehyde in PBS for $20 \mathrm{~min}$ at room temperature. Images were taken with a $4 \mathrm{X}$ objective on a Leica DM IL LED microscope (Leica Microsystems, Inc., Deerfield, IL, United States). Tube formation was analyzed with the Angiogenesis Analyzer plugin on ImageJ. Six images per well were analyzed, with four wells per group. Well totals were calculated and normalized to the No-EVs Control.

\section{Statistical Analysis}

Data were analyzed with a one-way ANOVA and Holm-Sidak post-test, when meeting the assumptions of normality and equal variance. A $p$-value $<0.05$ was considered statistically significant. All values are expressed as mean \pm SD.

\section{RESULTS}

\section{Cell Morphology and Cardiac Marker Expression of hCPCs}

Human CPCs were cultured at each oxygen concentration for $48 \mathrm{~h}$ with hypoxia which was achieved in a regulated hypoxia chamber at $37^{\circ} \mathrm{C}$ and $5 \% \mathrm{CO}_{2}$, with humidity. Phase microscopy images were taken and revealed that hCPCs showed no changes in cell morphology compared to normoxic $21 \% \mathrm{O}_{2}$ when subjected to low-oxygen (Figure 1). Immunofluorescent staining for cardiac markers NKX-2.5 and GATA-4 was preformed to confirm their cardiac lineage (Figure 1 and Supplementary Figures 1, 2), which confirmed that lowoxygen culture conditions did not alter their cardiac lineage. Similarly, immunostaining for c-kit was also performed and results showed that cells maintained c-kit expression under low-oxygen conditions as well (Figure 1 and Supplementary 


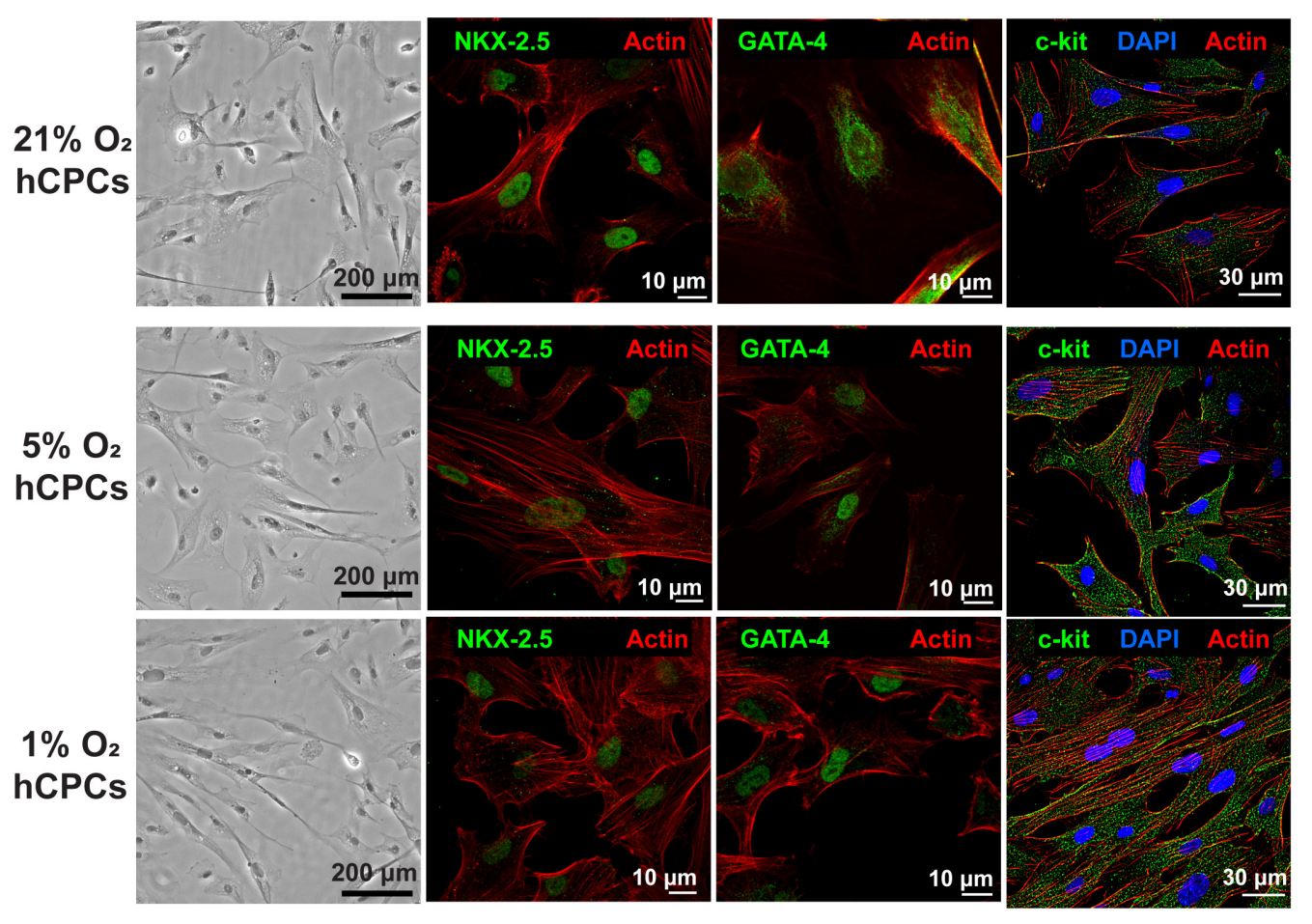

FIGURE 1 | hCPCs morphology and cardiac gene expression under normoxic and hypoxic microenvironments. Human CPCs were cultured under 21,5 , and $1 \%$ O 2 for $48 \mathrm{~h}$. DIC imaging shows the typical morphology of cells, which is unchanged under hypoxia. Immunofluorescent staining for cardiac lineage markers NKX-2.5 (green, nuclear), GATA-4 (green, nuclear), and c-kit (green) showed their expression was maintained under all oxygen conditions. Nuclei are stained blue and F-actin is stained red.

Figure 3). Therefore, low-oxygen culture did not affect CPC morphology or identity.

\section{Analysis of Cellular Health Under Hypoxic Culturing Conditions}

Hypoxia is known to negatively affect cellular health due to oxidative stress. To test whether $5 \% \mathrm{O}_{2}$ and $1 \% \mathrm{O}_{2}$ negatively affected cellular health we analyzed cell proliferation and cell death for all conditions. Cells were analyzed by XTT assay at time 0 and after $24 \mathrm{~h}$. Results demonstrated that cell proliferation was unchanged under either low-oxygen condition as compared to $21 \% \mathrm{O}_{2}$ (Figure $\mathbf{2 A}$ ), thus the cells were dividing as normal. Furthermore, cells were analyzed for apoptosis and cell death to determine whether culturing under low-oxygen conditions was stressful and induced apoptosis or necrosis. We incubated the cells under the three oxygen concentrations for $48 \mathrm{~h}$ then harvested and stained the cells with Annexin V-FITC and propidium iodide (PI) for analysis by flow cytometry. Results showed that the percentage of healthy cells (dual negative) is similar for all oxygen conditions (Figure 2B). Thus, culturing cells at 5 and $1 \% \mathrm{O}_{2}$ for $48 \mathrm{~h}$ did not induce apoptosis or necrosis.

\section{Changes in Cellular Gene Expression Under Varying $\mathrm{O}_{2}$ Environments}

A qPCR array for hypoxia-related genes was performed to assess the changes in gene expression of hCPCs under normoxic, physoxic, and hypoxic culture. Cellular gene expression was analyzed for all three oxygen conditions after $48 \mathrm{~h}$ of culture using an array with 84 genes involved in the hypoxia signaling pathway including: HIF1 $\alpha$ and its cotranscription factors and other interactors; hypoxic responsive genes involved in: angiogenesis, coagulation, DNA damage and repair, metabolism, regulation of apoptosis, regulation of cell proliferation, transcription factors, transporters, channels, receptors, and others. Data were normalized to five housekeeping genes and fold change was calculated relative to the normoxic cellular expression level. Culturing under $5 \% \mathrm{O}_{2}$ induced a significant $(p<0.05, n=3)$ increase in the expression of five genes (IGFBP3, EDN1, CA9, MMP9, VEGFA) and a significant $(p<0.05, n=3)$ decrease in the expression of four genes (NAMPT, PLAU, ODC1, EGR1) (Figure 3A). Culturing at $1 \% \mathrm{O}_{2}$ caused a significant $(p<0.05, n=3)$ increase in the expression of 23 genes (IGFBP3, BDRG1, CA9, ANGPLT4, MMP9, ADM, DDIT4, PGF, PFKFB3, SLC2A3, SLC2A1, ANKRD37, VEGFA, HK2, GPI, PDK1, ANXA2, BLM, LOX, TXNIP, PFKFB4, ERO1A, GBE1) and a significant $(p<0.05, n=3)$ decrease in the expression of eight genes (P4HA1, NAMPT, ADORA2B, TFRC, HIF1A, HMOX1, FOS, EGR1) (Figure 3B). While the upregulated genes show some commonality, increased expression of EDN1 was unique to $5 \% \mathrm{O}_{2}$ culture (Figure $3 \mathrm{C}$ ). Entire array data can be found in Supplementary Table 1. These results demonstrate that culturing hCPCs under $5 \% \mathrm{O}_{2}$ modulated 

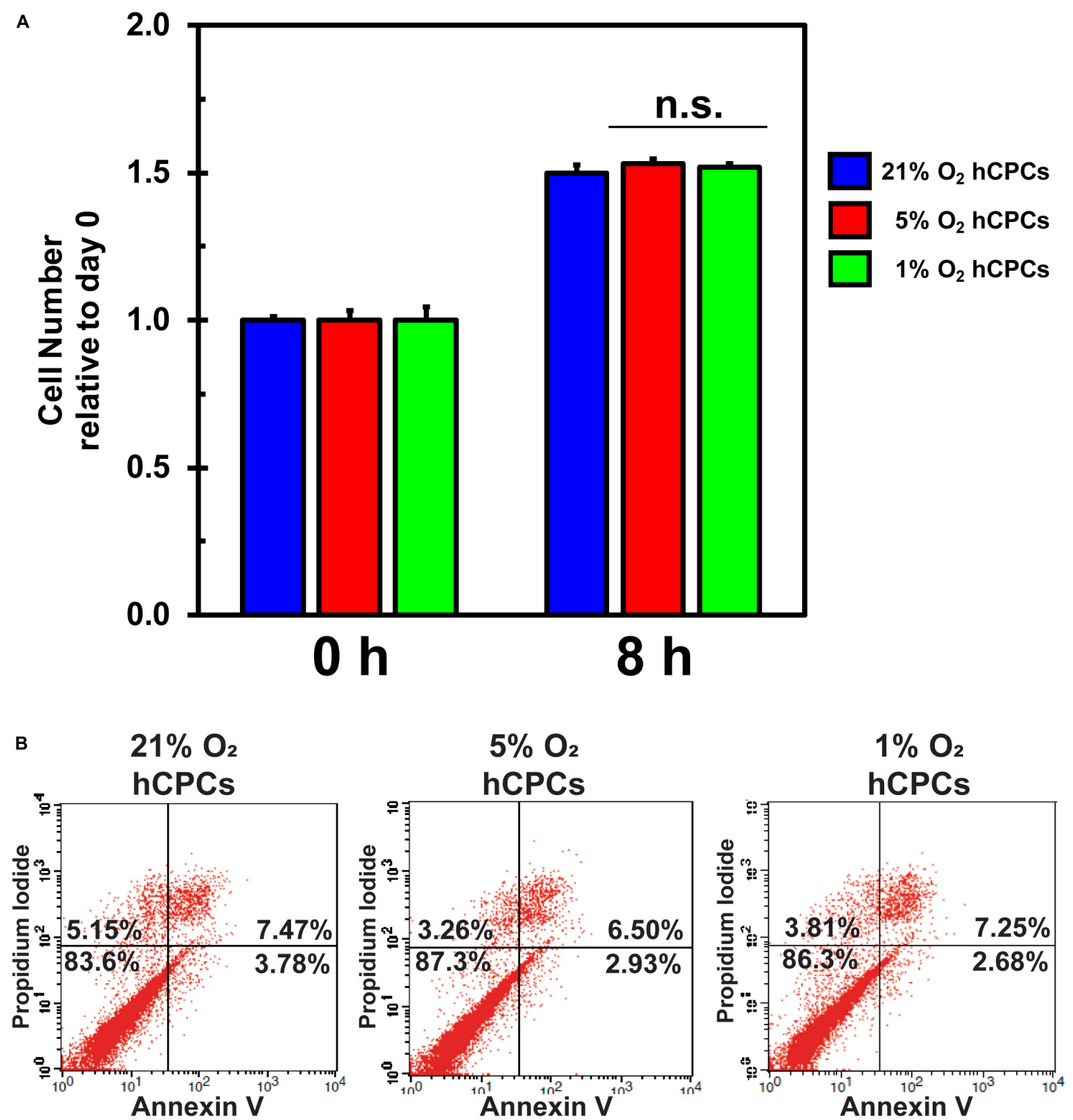

FIGURE 2 | hCPCs maintain normal function under hypoxia. hCPCs were cultured under 21, 5, and $1 \% \mathrm{O}_{2}$. (A) XTT assay for cell proliferation shows that cells maintained a similar level of proliferation over $24 \mathrm{~h}$. Data represents mean $\pm \mathrm{SD}, n=4$. (B) Flow cytometry for Annexin V/PI show that cells are equally healthy under the various oxygen conditions as the number of non-apoptotic/non-necrotic cells remains similar after $48 \mathrm{~h}$ of culture.

few hypoxia-related genes and culturing hCPCs under $1 \% \mathrm{O}_{2}$ modulated numerous hypoxic genes.

\section{Isolation and Characterization of hCPC-Derived EVs}

EVs were successfully isolated from hCPCs under all three $\mathrm{O}_{2}$ conditions and analyzed via Cryo-TEM to preserve their shape and structure. The lipid bilayer is easily identified in representative TEM images (Figure 4A, yellow arrows). EVs were further analyzed for common exosomal markers with an antibody array. To verify exosome identity, isolated particles were tested to comply with international standards (Thery et al., 2018) demonstrating at least three positive markers and one negative marker. Results show that these EVs expressed the exosomal transmembrane or lipid-bound markers ICAM, CD81, CD63, ANXA5, and cytosolic markers ALIX, FLOT-1 and TSG101 (Figure 4B) (de Gassart et al., 2003; Lotvall et al., 2014). Detection of the negative marker GM130 (Lotvall et al., 2014; Keerthikumar et al., 2015; Samaeekia et al., 2018), a Golgi-associated protein, was not seen, thus confirming their identity as exosomes. Detection patterns were similar for the EVs isolated under all 


\section{A $\quad 5 \% \mathrm{O}_{2} \mathrm{hCPCs}$}

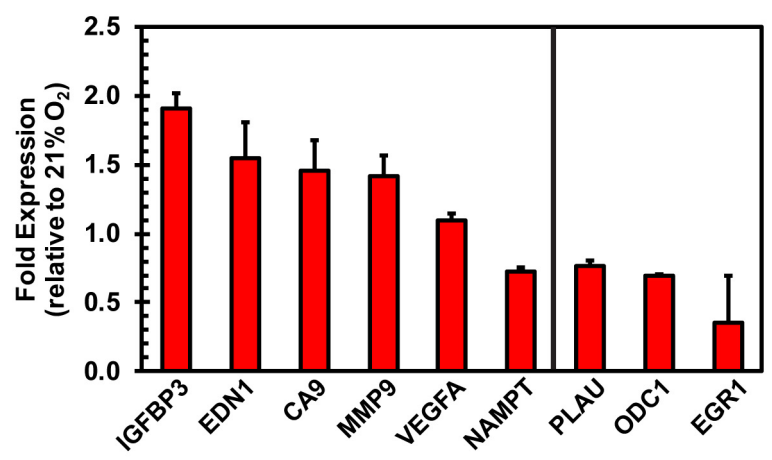

B $\quad 1 \% \mathrm{O}_{2} \mathrm{hCPCs}$

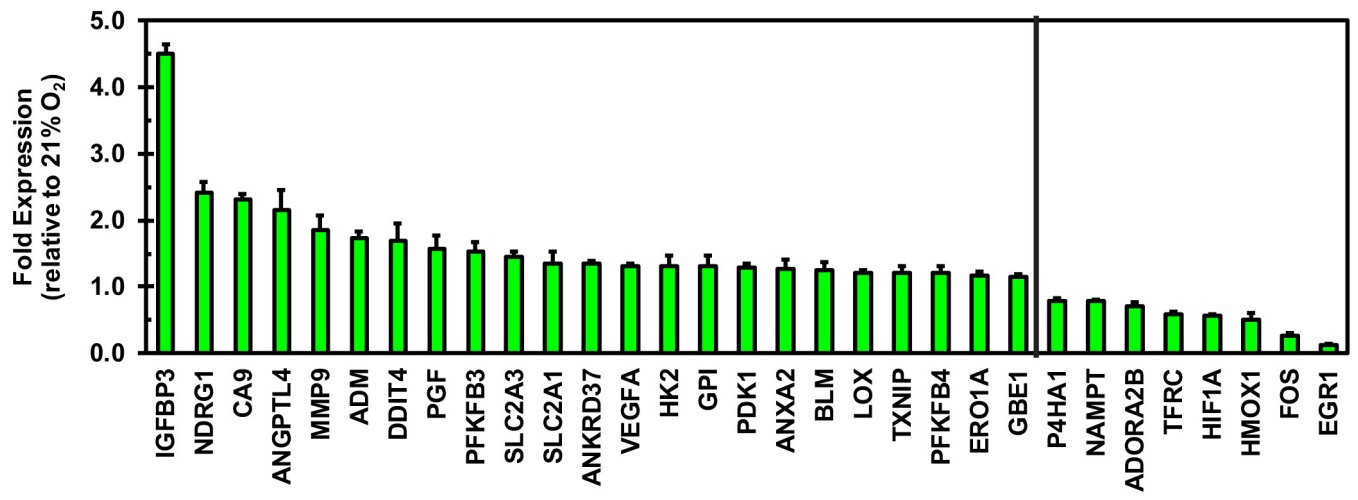

\section{c}
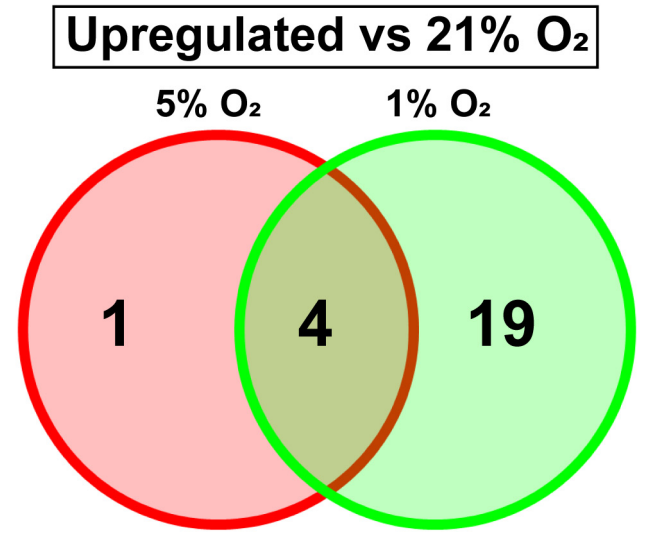

Downregulated vs 21\% $\mathrm{O}_{2}$

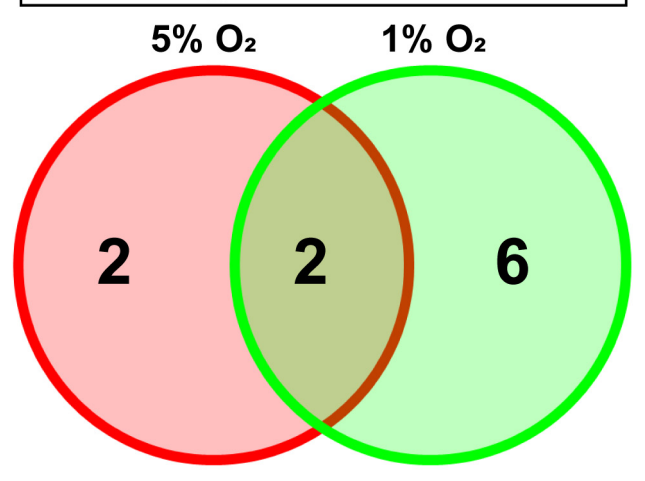

FIGURE 3 | Culturing hCPCs under hypoxia modulates hypoxic gene expression. hCPCs were cultured under 21,5 , and $1 \% \mathrm{O}_{2}$ for $48 \mathrm{~h}$ then total RNA was harvested and gene expression analyzed via real-time PCR. Gene expression was normalized to five housekeeping genes and calculated as a fold change relative to levels at $21 \% \mathrm{O}_{2}$. (A) $5 \% \mathrm{O}_{2}$ culturing of hCPCs significantly increased expression of five genes, and significantly decreased expression of four genes. Data represented as mean $\pm \mathrm{SD}, n=3$, all have $p<0.05$ as compared to $21 \% \mathrm{O}_{2}$. (B) $1 \% \mathrm{O}_{2}$ culture altered expression of numerous hypoxia-related genes. 23 genes were significantly increased in expression and 8 genes were significantly decreased in expression, as compared to $21 \% \mathrm{O}_{2}$. Data represented as mean $\pm \mathrm{SD}, n=3$, all have $p<0.05$ as compared to $21 \% \mathrm{O}_{2}$. (C) Venn diagram illustrating similarly and differentially regulated genes under 5 and $1 \% \mathrm{O}_{2}$, as compared to $21 \% \mathrm{O}_{2}$.

three oxygen conditions. Nanoparticle tracking analysis (NTA) revealed the size and concentration distribution for EVs derived from the three oxygen conditions (Figure 4C). Their sizes are consistent with those of exosomes (50-150 nm) (Yanez-Mo et al., 2015) and small microvesicles (100-1000 nm) (Cocucci and Meldolesi, 2015). The mean and mode sizes of the particles isolated from the differing oxygen concentrations were similar
(Figure 4D). Interestingly, concentration, and thus yield, of EVs was 1.6-fold greater under $5 \% \mathrm{O}_{2}$ conditions (Figure $4 \mathrm{E}$ ). Since EVs were isolated from identically seeded plates with equal volumes of media and were resuspended in identical volumes of PBS the concentration of EVs is congruent to their yield. Furthermore, this data showed that $5 \% \mathrm{O}_{2}$ EVs had a unique size distribution. Collectively, these data verify the identity of the 
A

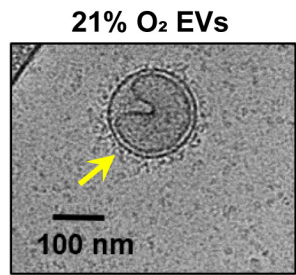

B

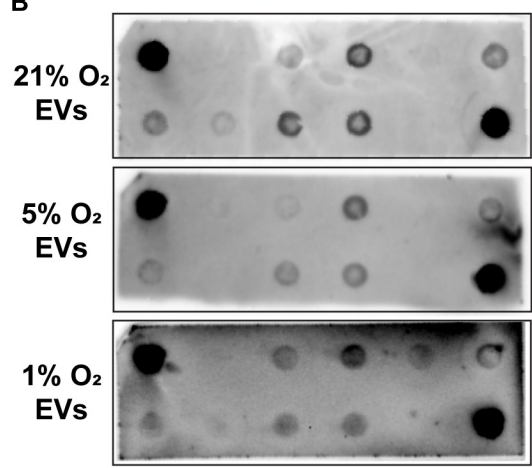

C

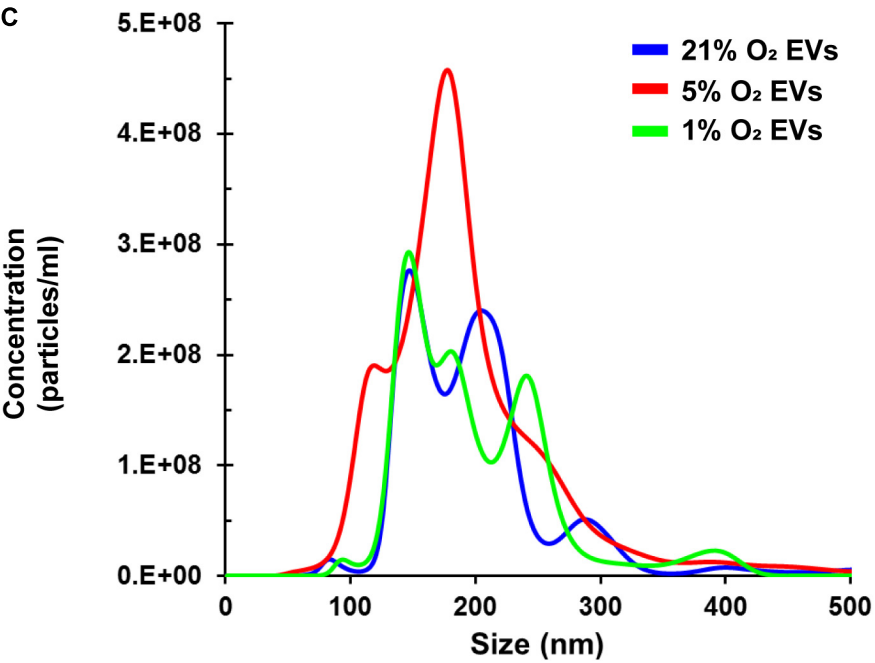

$1 \% \mathrm{O}_{2} \mathrm{EVs}$
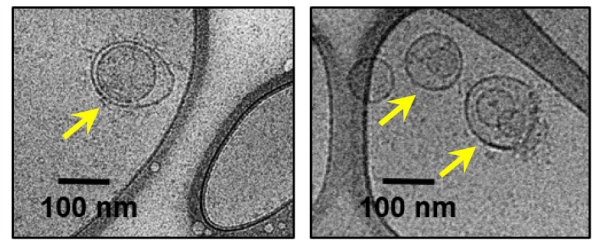

Exosome Array Layout Exosome Markers

Cytosolic Exosome Markers

Negative Exosome Marker

Array Positive Controls

Blank, Negative Control

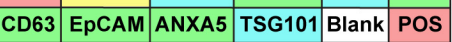

Transmembrane or Lipid-bound

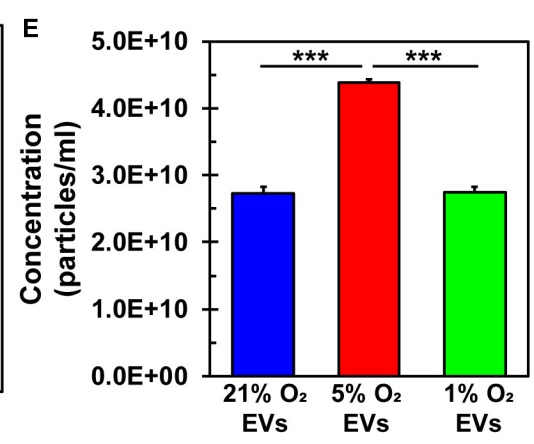

FIGURE 4 | Characterization of EVs derived from hCPCs under varying oxygen microenvironment. hCPCs were cultured under three different oxygen condition (21, 5 , and $1 \% \mathrm{O}_{2}$ ) to generate EVs for analysis. (A) Cryo-TEM of isolated EVs shows their characteristic morphology of a round shape with a lipid bilayer (yellow arrows), which was identified under all three conditions. (B) EVs derived from 21, 5, and 1\% $\mathrm{O}_{2}$ hCPCs were analyzed with an exosome antibody array for known exosome markers and a negative exosome marker. The isolated EVs from all three $\mathrm{O}_{2}$ conditions met the ISEV minimum requirements for identification. (C) NTA of triplicate samples shows the size and concentration distribution of EVs. (D) Mean and mode sizes of isolated EVs were similar and within the accepted range for extracellular vesicles, data is mean $\pm \mathrm{SD}, n=3$. (E) The concentration of EVs isolated from hCPCs cultured under $5 \% \mathrm{O}_{2}$ microenvironment was higher than 21 and $1 \% \mathrm{O}_{2}$ groups, data is mean $\pm \mathrm{SD}, n=3 .{ }^{\star \star} p<0.01,{ }^{\star \star *} p<0.001$. 
isolated particles to include small microvesicles and exosomes. Varying oxygen concentrations generated EVs that were similar in mean and mode size, however, their secretion was increased under $5 \% \mathrm{O}_{2}$ and also had a unique size distribution pattern as compared to 21 and $1 \% \mathrm{O}_{2}$ culture.

\section{Angiogenic Potential of hCPC-Derived EVs}

A key tenet of angiogenesis is cell migration as cells must migrate toward the formation site of the new vessel (Adair and Montani, 2010). The wound-healing/scratch assay is a well-established assay for 2-D cell migration (Rodriguez et al., 2005). BAECs were grown to confluence in 24-well plates, wounded with a pipet tip, and treated with hCPC EVs from 21,5 , and $1 \% \mathrm{O}_{2}$ culture at $100 \mu \mathrm{g} / \mathrm{ml} \mathrm{EVs} \mathrm{(total} \mathrm{EV} \mathrm{protein)} \mathrm{at} \mathrm{time} \mathrm{0.} \mathrm{Results} \mathrm{demonstrate}$ that all groups of EVs significantly increased BAEC migration after $8 \mathrm{~h}$ as compared to No-EVs control (Figure 5A). The $5 \% \mathrm{O}_{2}$-derived EVs had the greatest percentage wound closure, however, this was not statistically significant compared to 21 or $1 \% \mathrm{O}_{2}$ (Figure 5B). These results indicate that hCPC-derived EVs increase endothelial cell migration, a crucial component of angiogenesis, but this was not enriched by generation of EVs under hypoxic conditions.

Additionally, endothelial cells that are to form new blood vessels must reorganize into $3 \mathrm{D}$ tubules to allow for subsequent blood flow (Adair and Montani, 2010). The tube formation assay using ECs is a well-characterized model system for in vitro angiogenesis (Arnaoutova et al., 2009), which we used to assess the hCPC-derived EVs. BAECs were seeded with media containing $100 \mu \mathrm{g} / \mathrm{ml} \mathrm{EVs} \mathrm{(total} \mathrm{EV} \mathrm{protein)} \mathrm{from} \mathrm{21,}$ 5 , and $1 \% \mathrm{O}_{2}$ cultured hCPCs onto basement membranecoated wells and allowed to form tubules for $16 \mathrm{~h}$ (Figure 6A). Results demonstrate that treatment with $5 \% \mathrm{O}_{2}$-derived EVs has shown the greatest enhancement of tube formation. These EVs significantly ( $p<0.05, n=3$ ) increased the number of master junctions, total master segment length, and total mesh area as compared to No-EV control (Figure 6B). Impressively, 5\% $\mathrm{O}_{2}$ hCPC-derived EVs also significantly $(p<0.05, n=3)$ enhanced tube formation by all measurements as compared to both 21 and $1 \% \mathrm{O}_{2} \mathrm{EV}$ treatment (Figure 6B). Thus, culturing hCPCs at 5\% $\mathrm{O}_{2}$ generated EVs with the greatest angiogenic potential in terms of tube formation.

\section{DISCUSSION}

Overall, this study demonstrated the therapeutic potential of human CPC-derived EVs for cardiac repair. Our study elucidated the optimal oxygen concentration required for culturing hCPCs and showed that the EV-cargo released under $5 \% \quad \mathrm{O}_{2}$ is very potent for promoting angiogenesis. Furthermore, only a few hypoxic genes were modulated under $5 \% \mathrm{O}_{2}$ conditions, when compared to numerous genes altered under $1 \% \mathrm{O}_{2}$ culturing. Our results clearly demonstrate that physoxic $\left(5 \% \mathrm{O}_{2}\right)$ culturing of hCPCs may play a crucial role in myocardial repair applications, especially during cell transplantation studies to prevent hypoxic shock for transplanted
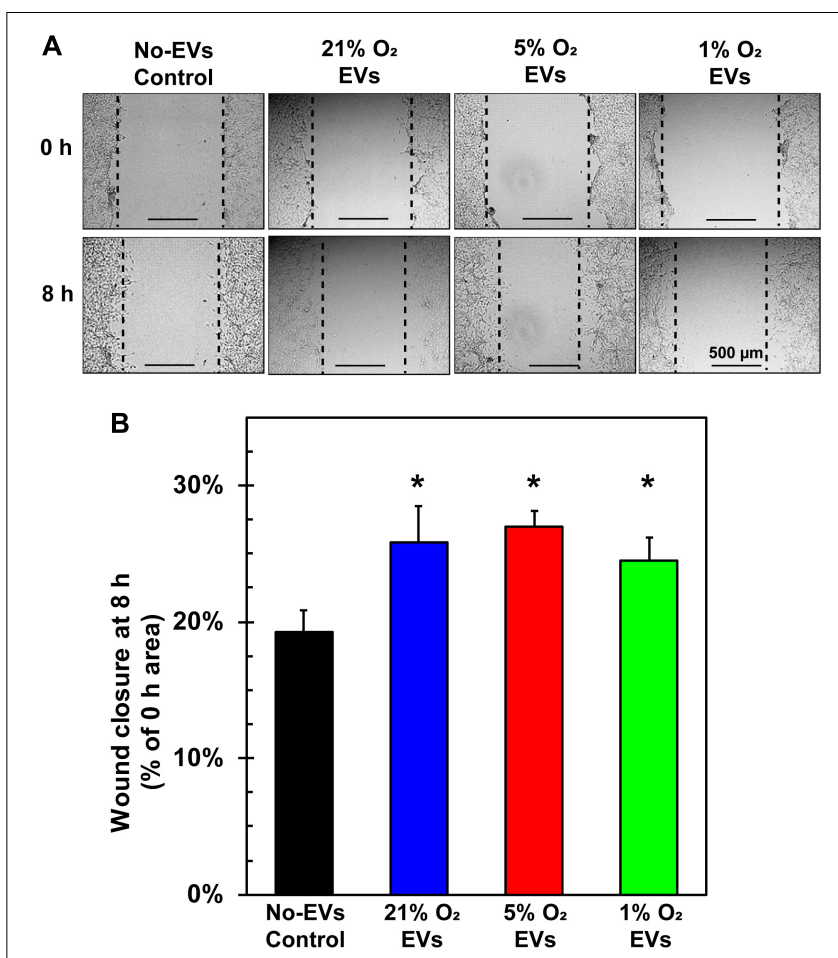

FIGURE 5 | Effect of hCPC-derived EVs on endothelial cell migration. BAECs were grown to confluence, wounded with a pipet tip, and treated with $100 \mu \mathrm{g} / \mathrm{ml}$ of total EV protein from each condition. (A) Representative images from 0 and $8 \mathrm{~h}$ show the extent of cell migration, with dotted lines approximating the cell front. (B) Wound healing assay demonstrates that treating ECs with hCPC-derived EVs increased cell migration significantly when compared to No-EVs group. However, no significant differences were observed between 5 and $1 \% \mathrm{O}_{2}$ derived $\mathrm{EV}$. Data are shown as mean $\pm \mathrm{SD}$, $n=4,{ }^{*} p<0.05$ vs. No-EVs control.

cells in the ischemic heart. Furthermore, physoxic culturing also influences the EV-cargo released by hCPCs as a source for cellfree therapeutics.

In this study, we have analyzed hCPCs and the functionality of their derived exosomes cultured under three different micro-environments $\left(21,5\right.$, and $\left.1 \% \mathrm{O}_{2}\right)$. Our results denote that hCPCs cultured under a low-oxygen, physiological microenvironment (a.k.a physoxic, 5\% $\mathrm{O}_{2}$ ) were able to maintain normal cell morphology and expression of cardiac markers, thereby demonstrating their robustness under physoxic oxygen conditions. NTA analysis indicated our ability to successfully isolate exosomes from cells under all oxygen conditions. Cells cultured at $5 \% \mathrm{O}_{2}$ exhibited increased exosome secretion with a unique size and concentration profile as compared to normoxia and $1 \% \mathrm{O}_{2}$ culturing. Functional assays from this study signify our novel hypothesis that physoxic oxygen concentration affects the therapeutic potential of hCPC-derived EVs. Additionally, gene expression profiling of the hCPCs revealed a possible molecular mechanism underlying the increased potency of $5 \% \mathrm{O}_{2}$-derived EVs. On the other hand, EDN1 was uniquely and significantly upregulated in $5 \% \quad \mathrm{O}_{2}$ cultured hCPCs when compared 


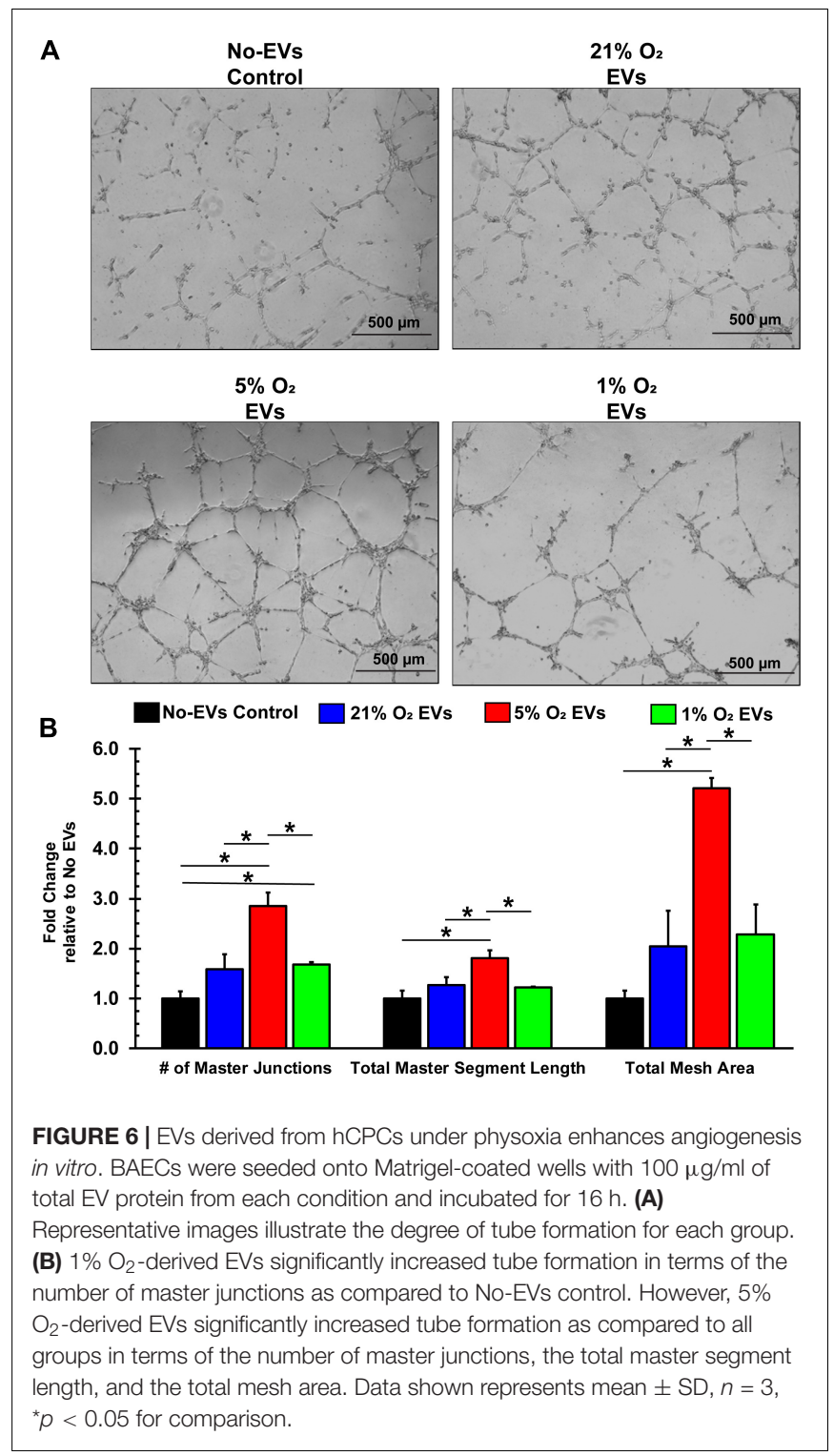

to normoxia or $1 \% \mathrm{O}_{2}$ cultured hCPCs. EDN1 encodes endothelin 1 (ET-1), a secreted peptide that acts as a paracrine signaling factor mediating growth (Soh et al., 2016), survival (Del Bufalo et al., 2002; Nelson et al., 2005), and angiogenesis (Salani et al., 2000; Wulfing et al., 2004; $\mathrm{Wu}$ et al., 2014). Future proteomic analysis of exosomes derived from $5 \% \mathrm{O}_{2}$ cultured hCPCs would reveal if EDN1 is delivered to target cells via exosomes and play a crucial role promoting angiogenesis.

Our NTA analysis results showed an increased EV release under $5 \% \quad \mathrm{O}_{2}$ condition, but not under at $1 \% \mathrm{O}_{2}$. Other studies have observed increased secretion of EVs under hypoxia (King et al., 2012; Bian et al., 2014; Zhu J. et al., 2018; Patton et al., 2019; Zhang et al., 2019), however these studies were not performed with hCPCs. Multiple studies have demonstrated enhanced functional effects of hypoxiaderived versus normoxia-derived EVs. A study of MSC-EVs observed increased proliferation, migration, and tube formation with hypoxia-derived EVs $\left(1 \% \mathrm{O}_{2}\right.$ for $\left.72 \mathrm{~h}\right)$ as compared to those from normoxic conditions (Bian et al., 2014). Another study on glioma cells observed significantly increased tube formation by endothelial progenitor cells when treated with hypoxia $\left(<0.5 \% \quad \mathrm{O}_{2}\right.$ for undisclosed time) versus normoxiaderived EVs; however, the treatments equally protected glioma cells from oxidative stress (Kore et al., 2018). Similarly, human cardiosphere-derived EVs isolated under 18 and $1 \% \mathrm{O}_{2}$ showed increased tube formation as compared to PBS control. However, the two conditions were either not analyzed to each other or their difference was not statistically significant (Namazi et al., 2018). Zhu L.P. et al. (2018), showed that intramyocardial implantation of EVs generated from BM-MSCs under hypoxia $\left(1 \% \mathrm{O}_{2}\right.$ for $\left.72 \mathrm{~h}\right)$ significantly decreased scar formation and improved cardiac function 28 days post-MI, as compared to normoxia-derived EVs. Overall, the results from our findings highlight the therapeutic potential of physoxia generated EVs as compared to normoxia-derived EVs. Wound healing assays showed that EV treatment significantly increased migration as compared to No-EVs control. Similarly, 5\% $\mathrm{O}_{2}$ hCPC-derived exosomes showed significant increase in tube formation as assessed by the number of master junctions, segment length, and mesh area as compared to both 21 or $1 \% \mathrm{O}_{2}$ EVs. Ultimately, $5 \% \mathrm{O}_{2}$ CPC-derived EVs in this study displayed the greatest therapeutic effect in vitro as a result of enhanced angiogenic behavior.

\section{CONCLUSION}

Promising results have stemmed from our study by assessing the therapeutic potential of hCPC-derived EVs under physoxia. Culturing hCPCs under physoxia showed increased EVs secretion and minimal changes in cellular expression of hypoxia-related genes. Future studies will focus on functional outcome of hCPC-derived EVs for myocardial repair in vivo and to perform proteomics and miRNA profiling of EV cargo to identify novel proteins and miRNAs modulated under physoxia.

\section{DATA AVAILABILITY STATEMENT}

The datasets generated for this study are available on request to the corresponding author.

\section{AUTHOR CONTRIBUTIONS}

MK, NP, and JD conceived and designed the experiments. MK, NP, JD, NK, SR, and HS performed the experiments and analyzed the data. MK, CC, HS, and MA contributed reagents, materials, and analysis tools. JD, NP, and MK wrote the first draft of the manuscript. All authors contributed to manuscript revision, read and approved the submitted version. 


\section{FUNDING}

This work was supported by the National Institutes of Health (HL136232 to MK, HL114951 to CC, and HL133050 to HS) and American Heart Association (18TPA34170188 to CC).

\section{ACKNOWLEDGMENTS}

We would like to acknowledge the OSUCCC Analytical Cytometry Core for performing flow cytometry analysis.

\section{REFERENCES}

Abdollahi, H., Harris, L. J., Zhang, P., McIlhenny, S., Srinivas, V., Tulenko, T., et al. (2011). The role of hypoxia in stem cell differentiation and therapeutics. J. Surg. Res. 165, 112-117. doi: 10.1016/j.jss.2009.09.057

Adair, T. H., and Montani, J. (2010). Overview of Angiogenesis: NCBI Resources. San Rafael, CA: Morgan and Claypool Life Science.

Ahadi, A., Brennan, S., Kennedy, J., Hutvagner, G., and Tran, N. (2016). Long noncoding RNAs harboring miRNA seed regions are enriched in prostate cancer exosomes. Sci. Rep. 6:24922. doi: 10.1038/srep24922

Arnaoutova, I., George, J., Kleinman, H. K., and Benton, G. (2009). The endothelial cell tube formation assay on basement membrane turns 20: state of the science and the art. Angiogenesis 12, 267-274. doi: 10.1007/s10456-009-9146-4

Bao, L., Meng, Q., Li, Y., Deng, S., Yu, Z., Liu, Z., et al. (2017). C-kit positive cardiac stem cells and bone marrow-derived mesenchymal stem cells synergistically enhance angiogenesis and improve cardiac function after myocardial infarction in a paracrine manner. J. Card Fail. 23, 403-415. doi: 10.1016/j.cardfail.2017.03. 002

Barile, L., Lionetti, V., Cervio, E., Matteucci, M., Gherghiceanu, M., Popescu, L. M., et al. (2014). Extracellular vesicles from human cardiac progenitor cells inhibit cardiomyocyte apoptosis and improve cardiac function after myocardial infarction. Cardiovasc. Res. 103, 530-541. doi: 10.1093/cvr/cvul67

Barile, L., Milano, G., and Vassalli, G. (2017). Beneficial effects of exosomes secreted by cardiac-derived progenitor cells and other cell types in myocardial ischemia. Stem Cell Investig. 4:93. doi: 10.21037/sci.2017.11.06

Benjamin, E. J., Blaha, M. J., Chiuve, S. E., Cushman, M., Das, S. R., Deo, R., et al. (2017). Heart disease and stroke statistics-2017 update: a report from the american heart association. Circulation 135, e146-e603.

Bian, S., Zhang, L., Duan, L., Wang, X., Min, Y., and Yu, H. (2014). Extracellular vesicles derived from human bone marrow mesenchymal stem cells promote angiogenesis in a rat myocardial infarction model. J. Mol. Med. 92, 387-397. doi: 10.1007/s00109-013-1110-5

Cavalier, A., Spehner, D., and Humbel, B. M. (2009). Handbook of Cryo-Preparation Methods for Electron Microscopy. Methods in Visualization. Boca Raton: CRC Press.

Choi, D. S., Kim, D. K., Kim, Y. K., and Gho, Y. S. (2015). Proteomics of extracellular vesicles: exosomes and ectosomes. Mass Spectr. Rev. 34, 474-490. doi: $10.1002 /$ mas. 21420

Cocucci, E., and Meldolesi, J. (2015). Ectosomes and exosomes: shedding the confusion between extracellular vesicles. Trends Cell Biol. 25, 364-372. doi: 10.1016/j.tcb.2015.01.004

Colombo, M., Raposo, G., and Thery, C. (2014). Biogenesis, secretion, and intercellular interactions of exosomes and other extracellular vesicles. Аnnu. Rev. Cell Dev. Biol. 30, 255-289. doi: 10.1146/annurev-cellbio-101512-122326

de Gassart, A., Geminard, C., Fevrier, B., Raposo, G., and Vidal, M. (2003). Lipid raft-associated protein sorting in exosomes. Blood 102, 4336-4344. doi: 10. 1182/blood-2003-03-0871

Del Bufalo, D., Di Castro, V., Biroccio, A., Varmi, M., Salani, D., Rosano, L., et al. (2002). Endothelin-1 protects ovarian carcinoma cells against paclitaxelinduced apoptosis: requirement for Akt activation. Mol. Pharmacol. 61, 524532. doi: $10.1124 / \mathrm{mol} .61 .3 .524$

den Haan, M. C., Grauss, R. W., Smits, A. M., Winter, E. M., van Tuyn, J., Pijnappels, D. A., et al. (2012). Cardiomyogenic differentiation-independent
We would also like to thank and acknowledge Dr. Min Gao of the Advanced Materials and Liquid Crystal Institute at Kent State University for performing cryoTEM experiments.

\section{SUPPLEMENTARY MATERIAL}

The Supplementary Material for this article can be found online at: https://www.frontiersin.org/articles/10.3389/fcell.2020.00130/ full\#supplementary-material

improvement of cardiac function by human cardiomyocyte progenitor cell injection in ischaemic mouse hearts. J. Cell Mol. Med. 16, 1508-1521. doi: 10.1111/j.1582-4934.2011.01468.x

Dougherty, J. A., Mergaye, M., Kumar, N., Chen, C. A., Angelos, M. G., and Khan, M. (2017). Potential role of exosomes in mending a broken heart: nanoshuttles propelling future clinical therapeutics forward. Stem Cells Int. 2017:5785436. doi: $10.1155 / 2017 / 5785436$

Gao, M., Kim, Y. K., Zhang, C., Borshch, V., Zhou, S., Park, H. S., et al. (2014). Direct observation of liquid crystals using cryo-TEM: specimen preparation and low-dose imaging. Microsc. Res. Tech. 77, 754-772. doi: 10.1002/jemt. 22397

Gezer, U., Ozgur, E., Cetinkaya, M., Isin, M., and Dalay, N. (2014). Long noncoding RNAs with low expression levels in cells are enriched in secreted exosomes. Cell Biol. Int. 38, 1076-1079. doi: 10.1002/cbin.10301

Gray, W. D., French, K. M., Ghosh-Choudhary, S., Maxwell, J. T., Brown, M. E., Platt, M. O., et al. (2015). Identification of therapeutic covariant microRNA clusters in hypoxia-treated cardiac progenitor cell exosomes using systems biology. Circ. Res. 116, 255-263. doi: 10.1161/CIRCRESAHA.116.304360

Grayson, W. L., Zhao, F., Bunnell, B., and Ma, T. (2007). Hypoxia enhances proliferation and tissue formation of human mesenchymal stem cells. Biochem. Biophys. Res. Commun. 358, 948-953. doi: 10.1016/j.bbrc.2007.05.054

Hergenreider, E., Heydt, S., Treguer, K., Boettger, T., Horrevoets, A. J., Zeiher, A. M., et al. (2012). Atheroprotective communication between endothelial cells and smooth muscle cells through miRNAs. Nat. Cell Biol. 14, 249-256. doi: $10.1038 /$ ncb2441

Hernandez, I., Baio, J. M., Tsay, E., Martinez, A. F., Fuentes, T. I., Bailey, L. L., et al. (2018). Short-term hypoxia improves early cardiac progenitor cell function in vitro. Am. J. Stem Cells 7, 1-17.

Keerthikumar, S., Gangoda, L., Liem, M., Fonseka, P., Atukorala, I., Ozcitti, C., et al. (2015). Proteogenomic analysis reveals exosomes are more oncogenic than ectosomes. Oncotarget 6, 15375-15396.

King, H. W., Michael, M. Z., and Gleadle, J. M. (2012). Hypoxic enhancement of exosome release by breast cancer cells. BMC Cancer 12:421. doi: 10.1186/14712407-12-421

Kore, R. A., Edmondson, J. L., Jenkins, S. V., Jamshidi-Parsian, A., Dings, R. M., Reyna, N. S., et al. (2018). Hypoxia-derived exosomes induce putative altered pathways in biosynthesis and ion regulatory channels in glioblastoma cells. Biochem. Biophys. Rep. 14, 104-113. doi: 10.1016/j.bbrep.2018.03.008

Krishna, K. A., Krishna, K. S., Berrocal, R., Rao, K. S., and Sambasiva Rao, K. R. (2011). Myocardial infarction and stem cells. J. Pharm. Bioallied. Sci. 3, $182-188$.

Lai, R. C., Arslan, F., Lee, M. M., Sze, N. S., Choo, A., Chen, T. S., et al. (2010). Exosome secreted by MSC reduces myocardial ischemia/reperfusion injury. Stem Cell Res. 4, 214-222. doi: 10.1016/j.scr.2009.12.003

Le, T., and Chong, J. (2016). Cardiac progenitor cells for heart repair. Cell Death Discov. 2:16052. doi: 10.1038/cddiscovery.2016.52

Livak, K. J., and Schmittgen, T. D. (2001). Analysis of relative gene expression data using real-time quantitative PCR and the 2(-Delta Delta C(T)) method. Methods 25, 402-408. doi: 10.1006/meth.2001.1262

Lotvall, J., Hill, A. F., Hochberg, F., Buzas, E. I., Di Vizio, D., Gardiner, C., et al. (2014). Minimal experimental requirements for definition of extracellular vesicles and their functions: a position statement from the International society for extracellular vesicles. J. Extracell. Vesicles 3:26913. doi: 10.3402/jev.v3.26913 
Maas, S. L. N., Breakefield, X. O., and Weaver, A. M. (2017). Extracellular vesicles: unique intercellular delivery vehicles. Trends Cell Biol. 27, 172-188. doi: 10. 1016/j.tcb.2016.11.003

McKeown, S. R. (2014). Defining normoxia, physoxia and hypoxia in tumoursimplications for treatment response. Br. J. Radiol. 87:20130676. doi: 10.1259/ bjr.20130676

Namazi, H., Mohit, E., Namazi, I., Rajabi, S., Samadian, A., Hajizadeh-Saffar, E., et al. (2018). Exosomes secreted by hypoxic cardiosphere-derived cells enhance tube formation and increase pro-angiogenic miRNA. J. Cell Biochem. 119, 4150-4160. doi: 10.1002/jcb.26621

Nelson, J. B., Udan, M. S., Guruli, G., and Pflug, B. R. (2005). Endothelin-1 inhibits apoptosis in prostate cancer. Neoplasia 7, 631-637. doi: 10.1593/neo.04787

Noort, W. A., Oerlemans, M. I., Rozemuller, H., Feyen, D., Jaksani, S., Stecher, D., et al. (2012). Human versus porcine mesenchymal stromal cells: phenotype, differentiation potential, immunomodulation and cardiac improvement after transplantation. J. Cell Mol. Med. 16, 1827-1839. doi: 10.1111/j.1582-4934.2011. 01455.x

Ohno, S., and Kuroda, M. (2016). Exosome-mediated targeted delivery of miRNAs. Methods Mol. Biol. 1448, 261-270. doi: 10.1007/978-1-4939-3753-0_19

Patton, M. C., Zubair, H., Khan, M. A., Singh, S., and Singh, A. (2019). Hypoxia alters the release and size distribution of extracellular vesicles in pancreatic cancer cells to support their adaptive survival. J. Cell Biochem. 121, 828-839. doi: $10.1002 /$ jcb. 29328

Prabhu, S. D., and Frangogiannis, N. G. (2016). The biological basis for cardiac repair after myocardial infarction: from inflammation to fibrosis. Circ. Res. 119, 91-112. doi: 10.1161/circresaha.116.303577

Raposo, G., and Stoorvogel, W. (2013). Extracellular vesicles: exosomes, microvesicles, and friends. J. Cell Biol. 200, 373-383. doi: 10.1083/jcb. 201211138

Record, M., Carayon, K., Poirot, M., and Silvente-Poirot, S. (2014). Exosomes as new vesicular lipid transporters involved in cell-cell communication and various pathophysiologies. Biochim. Biophys. Acta 1841, 108-120. doi: 10.1016/ j.bbalip.2013.10.004

Rehman, J., Traktuev, D., Li, J., Merfeld-Clauss, S., Temm-Grove, C. J., Bovenkerk, J. E., et al. (2004). Secretion of angiogenic and antiapoptotic factors by human adipose stromal cells. Circulation 109, 1292-1298. doi: 10.1161/01.cir. 0000121425.42966.f1

Rodriguez, L. G., Wu, X., and Guan, J. L. (2005). Wound-healing assay. Methods Mol. Biol. 294, 23-29.

Salani, D., Taraboletti, G., Rosano, L., Di Castro, V., Borsotti, P., Giavazzi, R., et al. (2000). Endothelin-1 induces an angiogenic phenotype in cultured endothelial cells and stimulates neovascularization in vivo. Am. J. Pathol. 157, 1703-1711. doi: 10.1016/s0002-9440(10)64807-9

Samaeekia, R., Rabiee, B., Putra, I., Shen, X., Park, Y. J., Hematti, P., et al. (2018). Effect of human corneal mesenchymal stromal cell-derived exosomes on corneal epithelial wound healing. Invest. Ophthalmol. Vis. Sci. 59, 5194-5200. doi: 10.1167/iovs.18-24803

Singh, H., Lu, R., Bopassa, J. C., Meredith, A. L., Stefani, E., and Toro, L. (2013). MitoBK $(\mathrm{Ca})$ is encoded by the Kcnmal gene, and a splicing sequence defines its mitochondrial location. Proc. Natl. Acad. Sci. U.S.A. 110, 10836-10841. doi: 10.1073/pnas.1302028110

Singh, H., Lu, R., Rodriguez, F., Wu, Y., Bopassa, J. C., Stefani, E., et al. (2012). Visualization and quantification of cardiac mitochondrial protein clusters with STED microscopy. Mitochondrion 12, 230-236. doi: 10.1016/j.mito.2011.09. 004

Soh, B. S., Ng, S. Y., Wu, H., Buac, K., Park, J. H., Lian, X., et al. (2016). Endothelin-1 supports clonal derivation and expansion of cardiovascular progenitors derived from human embryonic stem cells. Nat. Commun. 7:10774. doi: 10.1038/ ncomms 10774

Sullivan, R., Maresh, G., Zhang, X., Salomon, C., Hooper, J., Margolin, D., et al. (2017). The emerging roles of extracellular vesicles as communication vehicles within the tumor microenvironment and beyond. Front. Endocrinol. 8:194. doi: $10.3389 /$ fendo. 2017.00194

Thangarajah, H., Vial, I. N., Chang, E., El-Ftesi, S., Januszyk, M., Chang, E. I., et al. (2009). IFATS collection: adipose stromal cells adopt a proangiogenic phenotype under the influence of hypoxia. Stem Cells 27, 266-274. doi: 10.1634/ stemcells.2008-0276
Thery, C. (2011). Exosomes: secreted vesicles and intercellular communications. F1000 Biol. Rep. 3:15. doi: 10.3410/B3-15

Thery, C., Witwer, K. W., Aikawa, E., Alcaraz, M. J., Anderson, J. D., Andriantsitohaina, R., et al. (2018). Minimal information for studies of extracellular vesicles 2018 (MISEV2018): a position statement of the International society for extracellular vesicles and update of the MISEV2014 guidelines. J. Extracell. Vesicles 7:1535750. doi: 10.1080/20013078.2018. 1535750

van der Spoel, T. I., Vrijsen, K. R., Koudstaal, S., Sluijter, J. P., Nijsen, J. F., de Jong, H. W., et al. (2012). Transendocardial cell injection is not superior to intracoronary infusion in a porcine model of ischaemic cardiomyopathy: a study on delivery efficiency. J. Cell. Mol. Med. 16, 2768-2776. doi: 10.1111/j. 1582-4934.2012.01594.x

Wu, M. H., Huang, C. Y., Lin, J. A., Wang, S. W., Peng, C. Y., Cheng, H. C., et al. (2014). Endothelin-1 promotes vascular endothelial growth factor-dependent angiogenesis in human chondrosarcoma cells. Oncogene 33, 1725-1735. doi: 10.1038/onc.2013.109

Wu, S. Z., Li, Y. L., Huang, W., Cai, W. F., Liang, J., Paul, C., et al. (2017). Paracrine effect of CXCR4-overexpressing mesenchymal stem cells on ischemic heart injury. Cell Biochem. Funct. 35, 113-123. doi: 10.1002/cbf. 3254

Wulfing, P., Kersting, C., Tio, J., Fischer, R. J., Wulfing, C., Poremba, C., et al. (2004). Endothelin-1-, endothelin- A-, and endothelin-B-receptor expression is correlated with vascular endothelial growth factor expression and angiogenesis in breast cancer. Clin. Cancer Res. 10, 2393-2400. doi: 10.1158/1078-0432.ccr03-0115

Xiao, J., Pan, Y., Li, X. H., Yang, X. Y., Feng, Y. L., Tan, H. H., et al. (2016). Cardiac progenitor cell-derived exosomes prevent cardiomyocytes apoptosis through exosomal miR-21 by targeting PDCD4. Cell Death Dis. 7:e2277. doi: 10.1038/cddis.2016.181

Yanez-Mo, M., Siljander, R., Andreu, Z., Zavec, A. B., Borras, F. E., Buzas, E. I., et al. (2015). Biological properties of extracellular vesicles and their physiological functions. J. Extracell. Vesicles 4:27066. doi: 10.3402/jev.v4.27066

Zhang, L., Liu, H., Xu, K., Ling, Z., Huang, Y., Hu, Q., et al. (2019). Hypoxia preconditioned renal tubular epithelial cell-derived extracellular vesicles alleviate renal ischaemia-reperfusion injury mediated by the HIF-1alpha/Rab22 pathway and potentially affected by microRNAs. Int. J. Biol. Sci. 15, 1161-1176. doi: 10.7150/ijbs.32004

Zhang, S., Li, X., Jourd'heuil, F. L., Qu, S., Devejian, N., Bennett, E., et al. (2017). Cytoglobin promotes cardiac progenitor cell survival against oxidative stress via the upregulation of the NFkappaB/iNOS signal pathway and nitric oxide production. Sci. Rep. 7:10754. doi: 10.1038/s41598-017-11 342-6

Zhu, J., Lu, K., Zhang, N., Zhao, Y., Ma, Q., Shen, J., et al. (2018). Myocardial reparative functions of exosomes from mesenchymal stem cells are enhanced by hypoxia treatment of the cells via transferring microRNA-210 in an nSMase2dependent way. Artif. Cells Nanomed. Biotechnol. 46, 1659-1670. doi: 10.1080/ 21691401.2017.1388249

Zhu, L. P., Tian, T., Wang, J. Y., He, J. N., Chen, T., Pan, M., et al. (2018). Hypoxia-elicited mesenchymal stem cell-derived exosomes facilitates cardiac repair through miR-125b-mediated prevention of cell death in myocardial infarction. Theranostics 8, 6163-6177. doi: 10.7150/thno.28021

Zuo, S., Jones, W. K., Li, H., He, Z., Pasha, Z., Yang, Y., et al. (2012). Paracrine effect of Wnt11-overexpressing mesenchymal stem cells on ischemic injury. Stem Cells Dev. 21, 598-608. doi: 10.1089/scd.2011.0071

Conflict of Interest: The authors declare that the research was conducted in the absence of any commercial or financial relationships that could be construed as a potential conflict of interest.

Copyright (c) 2020 Dougherty, Patel, Kumar, Rao, Angelos, Singh, Cai and Khan. This is an open-access article distributed under the terms of the Creative Commons Attribution License (CC BY). The use, distribution or reproduction in other forums is permitted, provided the original author(s) and the copyright owner(s) are credited and that the original publication in this journal is cited, in accordance with accepted academic practice. No use, distribution or reproduction is permitted which does not comply with these terms. 